\title{
Design of remote control device using wireless sensor network and its use in intelligent monitoring of farmland information
}

\author{
Jian Zhang ${ }^{1 *}$ and Ying Wang ${ }^{2}$
}

\author{
*Correspondence: \\ zhangj@lzjtu.edu.cn \\ ${ }^{1}$ School of Art and Design, \\ Lanzhou Jiaotong University, \\ Gansu, China \\ Full list of author information \\ is available at the end of the \\ article
}

\begin{abstract}
The purpose is to control the growth state of crops remotely, design intelligent detection application of farmland information and improve the efficiency of agricultural information management. Wireless sensor technology is applied to remote control device. First, through the integration of the system functions that need to be completed in the farmland remote monitoring, the module requirements of the device are further determined. Finally, the overall design is determined. From the aspects of hardware, such as the selection of sensors, RF transceivers and software (such as data processing center module), remote control device is designed, and the detection and collection of farmland real-time information is completed. The results show that the communication distance of wireless sensor nodes can reach $215 \mathrm{~m}$ under the test condition of $0.5 \mathrm{~m}$ in open space. The research content can help people improve the understanding of crop growth environment and growth situation, and then help people improve work efficiency, and finally contribute to the process of agricultural informatization.
\end{abstract}

Keywords: Wireless sensor, Remote control, Intelligent monitoring, Farmland information collection

\section{Introduction}

Before the advent of the twenty-first century, wireless sensor networks (WSN) have been invented, and the earliest WSN is mainly used in the military field. As the development of the times, because of its wireless sensing characteristics, it is also gradually widely used in petrochemical industry, industrial manufacturing, agriculture and other fields $[1,2]$. At the end of last century, Gregory J, a researcher in the USA, made a new elaboration on the concept of WSN. In addition, with the advent of the twenty-first century, more and more people have found the unlimited prospects of WSN, and the important characteristics of its "wireless transmission" are widely concerned by researchers from all walks of life [3]. Foreign international business machine companies have put forward the concept of "Smarter Planet" for a long time; in China, China's top leaders have constantly put forward the concept of "reading China" based on WSN. Moreover, large-scale foreign wireless communication companies and chip manufacturers, such

(c) The Author(s) 2021. This article is licensed under a Creative Commons Attribution 4.0 International License, which permits use, sharing, adaptation, distribution and reproduction in any medium or format, as long as you give appropriate credit to the original author(s) and the source, provide a link to the Creative Commons licence, and indicate if changes were made. The images or other third party material in this article are included in the article's Creative Commons licence, unless indicated otherwise in a credit line to the material. If material is not included in the article's Creative Commons licence and your intended use is not permitted by statutory regulation or exceeds the permitted use, you will need to obtain permission directly from the copyright holder. To view a copy of this licence, visit http://creativecommons. org/licenses/by/4.0/. 
as TI and Intel, start their independent research process early and continue to launch new WSN-related products. Moreover, foreign universities and manufacturing industry also constantly bring forth new ideas in this area; in China, China's well-known Internet communication companies, such as Huawei and ZTE, have also launched their own WSN and systems. In addition, China's major universities also make progress in WSN research.

In addition, Germany began to study agricultural informatization in the 1960s. After the 1970s, they invested a lot of money in the construction of agricultural database. In the mid-1980s, German agricultural database and expert system resources have been quite perfect, including pesticide spraying, pest control, fertilization, irrigation and other aspects. At the beginning of this century, in addition to the national level, the states under their jurisdiction have also developed their own comprehensive management platform of agricultural informatization, providing information inquiry and consulting services to farmers through various media. In 2013, aiming at the special climate environment in Greece, with the growth of crops in harsh environment as the research focus, Greek scholars mainly used DASHTMode technology to effectively improve the environmental conditions based on the real-time measurement of crop growth environment parameters, and finally realized the effective regulation of the harsh environment, which provided a new idea for the crop growth problems in the harsh climate. The process of agricultural informatization in Japan is also accelerating year by year. According to statistics, more than $40 \%$ of Japan's agricultural production has completely relied on the Internet of things technology. Meanwhile, in addition to the remote automatic collection of agricultural information, Japan has also developed lots of monitoring systems and information release platforms in water-saving irrigation, soil improvement and weather prediction, to support agricultural production through multiple channels. In China, in 2013, Dr. Zhang Wei of Zhejiang University combined sensor, distributed information processing and embedded development technology to realize real-time monitoring and control of agricultural information. In 2014, Wang Fengchun and Li Fengju of Tianjin Academy of Agricultural Sciences designed a temperature and humidity monitoring system based on wireless transmission for the agricultural greenhouse scene, which realized the real-time collection and collation of environmental data and crop parameters in the greenhouse. At present, many agricultural greenhouses have been built in China. They have real-time information collection system, database system and expert support and decision-making system, which can basically implement the main functions of agricultural Internet of things. With the completion of the 13th fiveyear plan for the development of agricultural and rural informatization, there are more and more examples of applying WSN to farmland information management. However, there are still some problems, such as the detection data is not perfect, the user function is not full, and it cannot meet the needs of analyzing the detected data [4]. At the hardware level, there are four parts: sensor module, microprocessor module, RF transceiver module and power module; at the software level, there are two parts: underlying software and data software.

This exploration aims to design an intelligent remote control device which can monitor the farmland information in real time through the use of WSN technology and the combination of software and hardware. The innovative points of the device 
are as follows. (1) There are enough sensor types in the device, which fully considers various factors in the farmland environment; (2) in the software level, the user part is added, so that the user can directly control the device remotely; (3) the data management module can not only manage the data in real time, but also back up and process the data; (4) the device can be changed for different applications through the change of the sensor. It is very important to solve the energy problem in the agricultural Internet of things monitoring system and design a sustainable farmland monitoring system which can be popularized in large areas of field farmland.

\section{Method}

\subsection{Overall design scheme of remote control device based on WSN}

Managers only need to place the wireless sensor nodes in the target area they want to monitor, and the wireless sensor nodes will automatically generate the wireless network. At this time, wireless sensors begin to collect sensing information and transmit it to the host, so that managers can monitor the situation in the area in real time. Figure 1 shows the functions of the three nodes of WSN.

According to the needs of innovation, this exploration aims to design a device that can complete the collection of farmland information, the transmission of farmland information and the information analysis of user terminal [5]. The structure of WSN remote control device based on farmland information monitoring application is mainly divided into three levels, and Fig. 2 is the design process.

The whole structure system is divided into three layers. The first layer includes two parts: terminal node and router node, where sensors are arranged to collect real-time information of farmland; the second layer is composed of coordinator node and general wireless packet service module, which collects and processes the farmland information transmitted here, and prepares for outward transmission; the third layer is composed of mobile communication network and remote terminal. The information

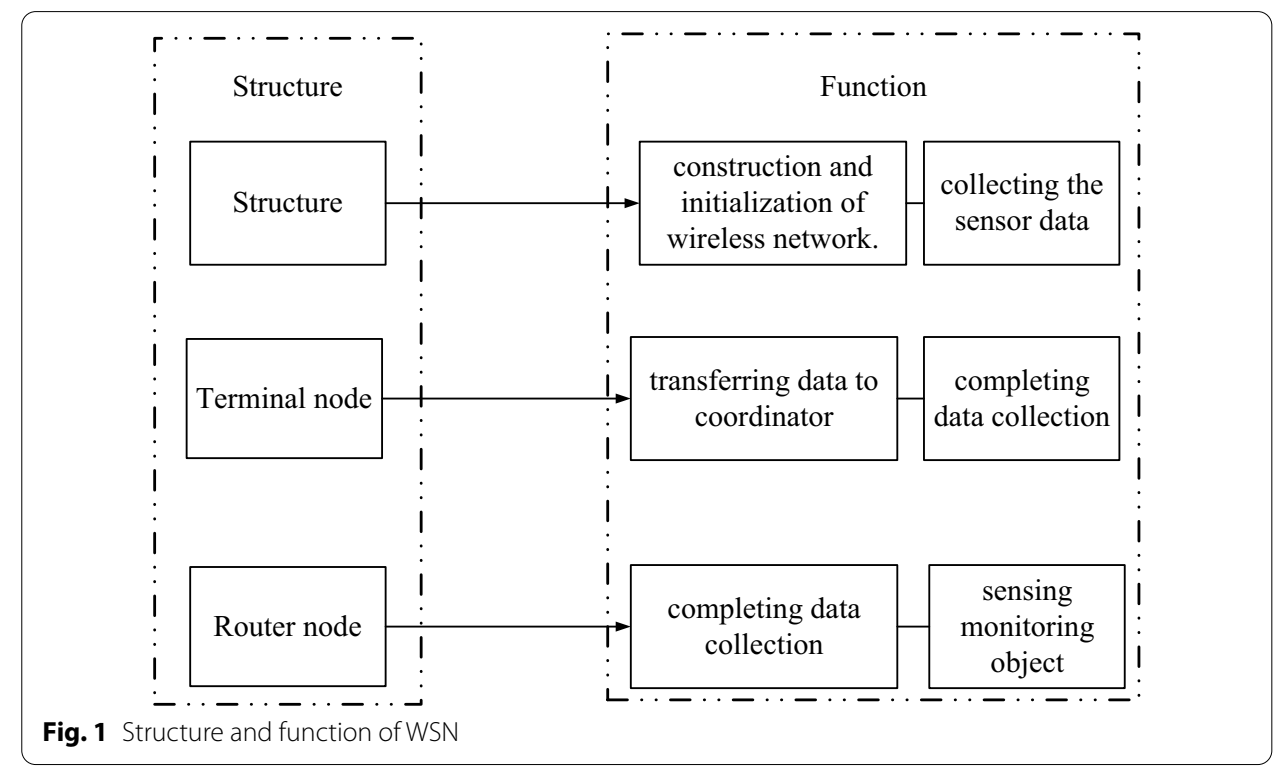




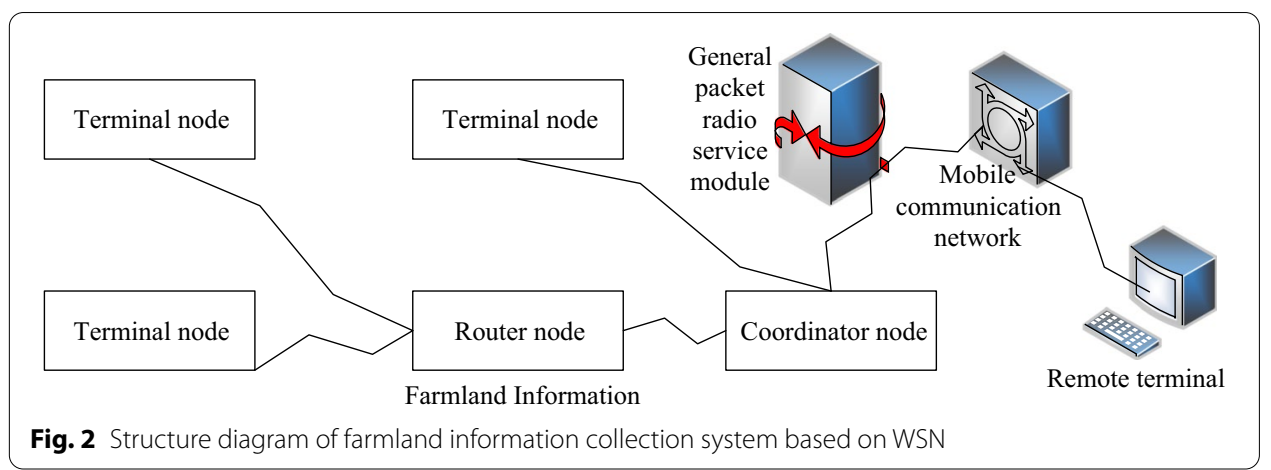

is transmitted to the terminal through the mobile communication network, and the terminal part can carry out a series of operations on the information.

In order to measure the communication range in the farmland environment, first, an equivalent variable experiment is carried out in an open field. The test conditions are determined as follows: $25^{\circ} \mathrm{C}$, sensor node height $0.5 \mathrm{~m}$, sensor input voltage $3 \mathrm{~V}$ and transmission frequency $0 \mathrm{dbm}$. Under such test conditions, the communication range is $215 \mathrm{~m}$.

\subsection{Hardware level design}

At present, wireless communication network is a hot spot in the field of agricultural environmental detection, and it has become the main way of traditional agricultural cultivation in China. The network runs lots of wireless sensor nodes, and the energy of field nodes is limited and inconvenient to replace. The energy problem has become a major problem restricting the development and promotion of agricultural information detection system. In order to solve this problem, this exploration is to study from two aspects: improving the power supply mode of nodes and optimizing the routing transmission algorithm to solve the problem of energy limitation. In the research process, CC1101RGPR remote control device is selected. Sensor module collects information data of environmental factors, and environmental factors always affect the environmental quality of farmland. People monitor it because it is related to whether crops can grow well. Therefore, the real-time information collection of farmland environment is particularly important. In order to obtain all-round real-time information of farmland environment, people choose wireless sensors from multiple angles and place them in the areas that need to be monitored. All kinds of sensors such as soil temperature, soil moisture, soil moisture, light, carbon dioxide and PH-YL rainfall, purchased from a technology company, are used. Due to the limited space, it is not listed here one by one. The data of carbon dioxide, temperature and humidity, light intensity and so on are used in the case test. Table 1 shows several sensors applied in the device and their relevant parameters.

As an important part of device hardware, it is very important to select the appropriate microcontroller. STM (synchronous transfer module) series microcontrollers produced by ST are widely used in power electronic systems, such as motor drive, application control and so on. As an enhanced microprocessor, STM32F103R8T6 has better performance [6]. Using high-performance Cortex-M3 core with the highest working frequency 
Table 1 Sensors and related parameters applied in device

\begin{tabular}{|c|c|c|c|c|c|}
\hline Types & $\begin{array}{l}\text { Water level } \\
\text { sensor }\end{array}$ & $\begin{array}{l}\text { Water } \\
\text { temperature } \\
\text { sensor }\end{array}$ & $\begin{array}{l}\text { Air temperature } \\
\text { and humidity } \\
\text { sensor }\end{array}$ & Light sensor & $\begin{array}{l}\text { Carbon dioxide } \\
\text { concentration } \\
\text { sensor }\end{array}$ \\
\hline Function & $\begin{array}{l}\text { Measuring } \\
\text { water level of } \\
\text { farmland }\end{array}$ & $\begin{array}{l}\text { Measuring water } \\
\text { temperature of } \\
\text { farmland }\end{array}$ & $\begin{array}{l}\text { Measurement of } \\
\text { air temperature } \\
\text { and humidity } \\
\text { in farmland }\end{array}$ & $\begin{array}{l}\text { Measurement } \\
\text { of light } \\
\text { intensity in } \\
\text { farmland }\end{array}$ & $\begin{array}{l}\text { Measurement of } \\
\text { carbon dioxide } \\
\text { concentration } \\
\text { in farmland }\end{array}$ \\
\hline $\begin{array}{l}\text { Related param- } \\
\text { eters }\end{array}$ & $\begin{array}{l}\text { Voltage } 12-36 \mathrm{~V} \\
\text { The measur- } \\
\text { ing range is } \\
0-0.5 \mathrm{~m}\end{array}$ & $\begin{array}{c}\text { Voltage } 3-5 \mathrm{~V} \\
\text { The measur- } \\
\text { ing range is } \\
0-100{ }^{\circ} \mathrm{C}\end{array}$ & $\begin{array}{l}\text { Voltage } 2.4-5.5 \mathrm{~V} \\
\text { Temperature } \\
\text { measur- } \\
\text { ing range } \\
-40-124^{\circ} \mathrm{C} \\
\text { Humidity meas- } \\
\text { urement range } \\
0-100 \%\end{array}$ & $\begin{array}{l}\text { Light intensity } \\
\text { range } \\
0-20,000 \mathrm{~lx} \\
\text { Spectral range } \\
320-730 \mathrm{~nm}\end{array}$ & $\begin{array}{l}\text { Voltage } 3.3 \mathrm{~V} \\
\text { measuring range } \\
0-20,000 \mathrm{ppm}\end{array}$ \\
\hline
\end{tabular}

of $72 \mathrm{MHz}$, it can complete a variety of algorithms. $1 \mu$ s dual 12-bit analog-to-digital conversion supports a variety of peripherals. Asynchronous transmission can transmit and receive up to 4 megabits per second. Meanwhile, it has very low power consumption, $36 \mathrm{~mA}$ at $72 \mathrm{MHz}$ and $2 \mu \mathrm{A}$ at standby; the working, standby, sleep and other modes can be switched at any time [7]. It is highly integrated with reset circuit, voltage regulator, resistor capacitor oscillation circuit and so on, with 2.0-3.6 V low supply voltage, and $5 \mathrm{~V}$ compatible input and output pins. It can work at -40 to $80{ }^{\circ} \mathrm{C}$ and meet the demand of hardware device.

According to the different transmission signals, sensors can be divided into digital sensors and analog sensors. The analog sensor outputs analog signal, and the digital signal is obtained through $\mathrm{A} / \mathrm{D}$ conversion and sent to the processor for processing. The digital sensor can directly output digital signal without analog-to-digital conversion, which is more convenient. The wireless communication capability of sensor nodes is limited, and the bandwidth is usually only a few hundred kbps. However, the farmland environment is wide, which requires lots of sensor nodes to cover the monitoring area. Because the sensor node is generally battery powered, its sensor should meet the requirements of small size, low power consumption and simple peripheral circuit, so digital sensor is a better choice.

RF transceiver is widely used in remote sensing, telemetry and other wireless communication fields. As an important part of wireless sensor node, people hope that the transceiver can have good performance and low power consumption [8]. Here, CC1101RGPR, one of the CC1101 series chips made by Texas Instruments, is selected. This kind of chip packaging method is VQFN (Very-thin quad flat no-lead), which is characterized by light weight and excellent thermal conductivity [9]. The weight of CC1101PGPR chip is only $70 \mathrm{mg}$. CC1101PGRP chip can analyze and sort out the transmitted information, and adjust the transmitted signal. Meanwhile, the ability of information transmission is also determined by the radio frequency transceiver. The chip with stronger transmission ability is also better. The maximum data transmission frequency of CC1101PGRP is $500 \mathrm{~kb} / \mathrm{s}$, which perfectly meets people's requirements for data transmission [10]. The receiving range of power supply voltage is $1.8-3.6 \mathrm{~V}$, which indicates that it has very low power consumption. The interface type is SPI, which makes the communication interface connection easier. At the same time, the sensitivity of the chip is very high, up to 
$-116 \mathrm{dBm}$. Finally, the chip also has humidity sensitivity, the working temperature range is $-40-85{ }^{\circ} \mathrm{C}$, and it can adapt to the needs of the working environment. Therefore, CC1101PGRP is the best choice here.

In order to meet the demand of continuous use of WSN remote control device based on farmland information monitoring, an energy storage battery and solar panels are installed for it. Moreover, from the design of each module, it is not feasible to only rely on the output voltage of $12 \mathrm{~V}$, because the input voltage of other modules may be very low and too high voltage will burn the circuit. The high input voltage is converted to the low voltage which can meet the requirements of the design module. Figure 3 is deep circuit design.

In Fig. 3, P1 is the external power inlet, 7850 is the voltage regulator, and U25 is the output interface. The current input from P1 will change from 12 to $5 \mathrm{~V}$ after U25 output through 7805 voltage regulator. The circuit design diagram reveals that the initial voltage given by the designed circuit can meet the input voltage requirements of all sensors except the water level sensor, and the output voltage of the voltage conversion circuit can also meet the input voltage requirements of $2.0-3.6 \mathrm{~V}$ for the microcontroller and 1.8-3.6 V for the RF transceiver.

\subsection{Software level design}

The overall planning and design of the device shows that there are two directions in the design of software level.

(1) Design of underlying WSN software: first, the coordinator is designed. Figure 4 suggests that in the whole process, the wireless network is established first, and then wireless signal acquisition is carried out. After the signal acquisition is completed, whether the data information is collected should be determined. Finally, the collected information is transmitted to the wireless service packet module. It should be noted that once the wireless signal is not obtained or the data packet is not received, the establishment of the wireless network should be restarted. The above steps are repeated, which is the function design of the coordinator.

Router node design: router node function has two branches. First, it is necessary to join the wireless network. After the successful success to wireless network, the operation of wireless data collection is carried out. After the operation is completed, the data

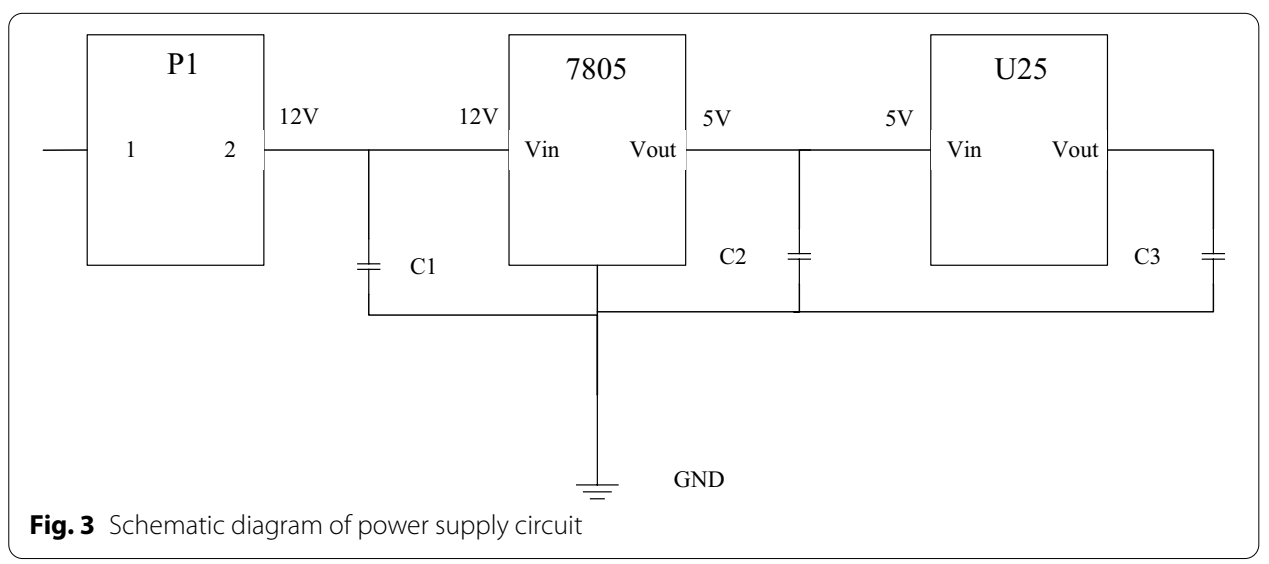



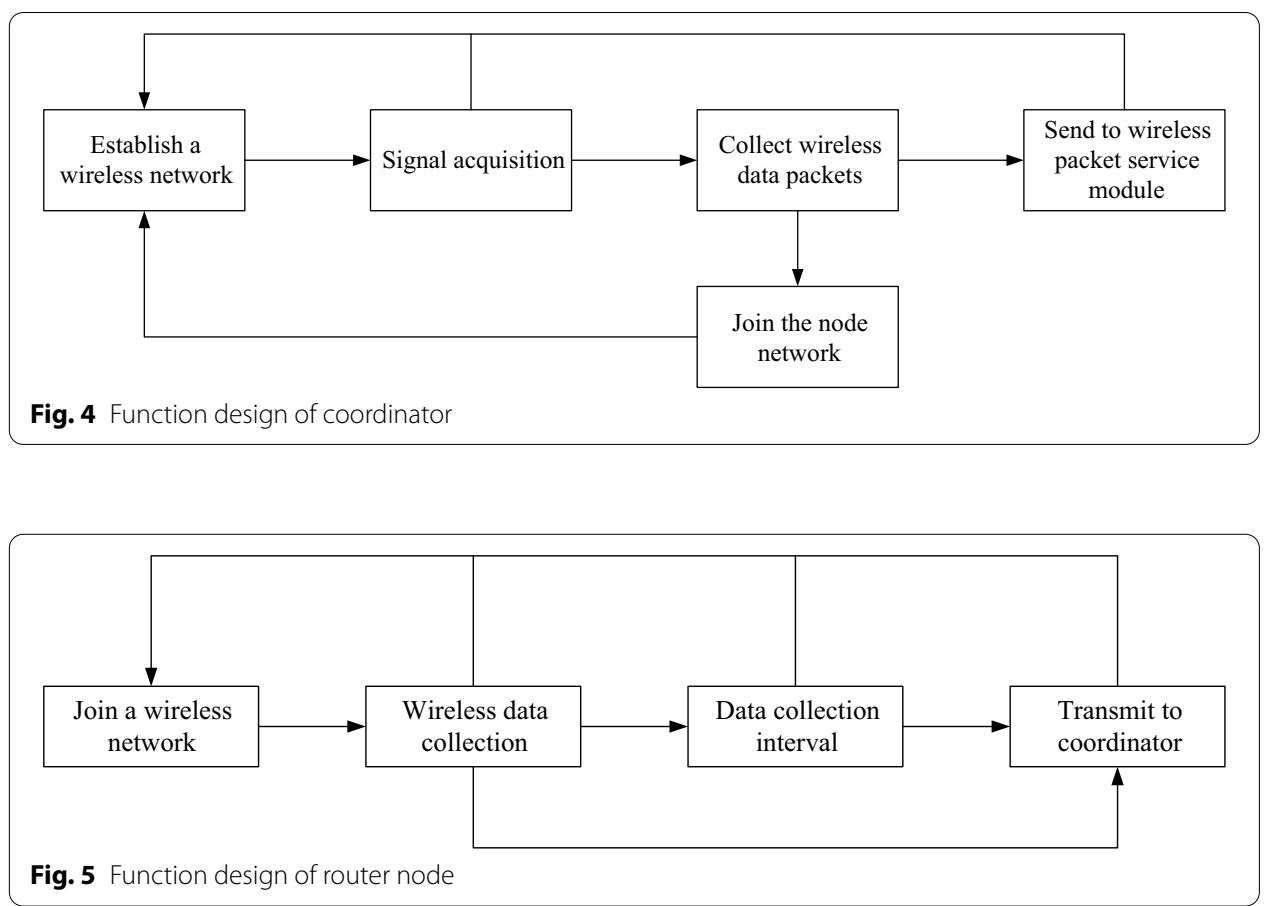

is transmitted directly to the sensor. If no packet is collected, it is necessary to continue to move forward to further check whether the data interval is collected. Finally, the collected data interval is transmitted to the coordinator. In the above steps, when a step is not completed, it is necessary to return to the process of whether to join the wireless network to start again. Figure 5 shows the design.

As the bottom layer of WSN, terminal node plays the role of information collection [11]. Terminal node design: terminal nodes need to join the wireless network to be applied. First, the key nodes need to apply to join the wireless network, and then whether joining the wireless network is successful is judged. If it is not successful, it is necessary to continue to judge whether or not the income is successful. If it is successful, information and data are collected through sensors. After the collection is successful, the RF transceiver CC1101 begins to sleep, and the microcontroller also enters the sleep state. It should be noted that a sleep wake-up time cycle should be set. Once the time is up, the microprocessor will wake up again.

(2) Data center software design:

a. User management part: it is the premise that people can use the designed device. In this section, four main functions are set. The first function is new account creation. This part is mainly the login setting for the user before the device operation. This section is to collect the new account information. After creation, the user can log in to the device for operation. Here, two kinds of accounts are set according to different login account requirements, which are management account and general account. The second function is account change. In this part, the function of the farmland detection system can be modified through the platform, and the information of the created account can also be modified. The management account has more author- 
ity to approve the modification application of general account. The third function is account cancellation. In this part, the relevant contents of the registered but no longer used accounts in the farmland monitoring system can be deleted. Similarly, the management account here still has more authority. It can be cancelled directly in the system. The last function is function setting. By assigning different requirements to different accounts, account processing function can be added to the management account based on general account. Only accounts with assigned functions can perform a series of operations.

b. Monitoring and management part: different from the initial function of user management part, monitoring and management part is an indispensable part for the designed device to work normally [12]. In this part, the monitoring module is set to operate the information data and four functions are also set: monitoring point operation, monitoring time operation, intercepting fragment operation and starting and ending operation.

c. Data management part: this part is the real operation part of the user login account. As an important part of the operating system, data management plays a fundamental role in a series of operations to collect farmland information [13]. It includes the functions of pattern analysis and processing in farmland monitoring, and it can copy, delete and maintain the data collected by farmland monitoring, and find these data in real time.

d. Data analysis part: as one of the data analysis methods, comparative analysis method is most widely used in daily life, so it is also adopted here. The relevant data collected by sensors in the farmland monitoring system in different periods are compared through the method of dynamic comparison. Different two-dimensional coordinate axes are set to analyze and compare the temperature, humidity, light intensity and other indexes in different time periods.

\section{Results and discussion}

\subsection{Test and result of communication range in farmland environment}

The experiment of communication range in farmland environment is carried out. In the farmland, the growth of different crops is not the same, and because of this difference, the measured communication range is also different [14]. Therefore, in this experiment, the wireless sensor is set at different heights of farmland, so as to study the communication range under this variable. When the environment changes to farmland, the temperature is still $25^{\circ} \mathrm{C}$; the input voltage and the emission frequency remain unchanged. Table 2 shows the values measured at different heights.

Table 2 shows that with the increase in placement height, when the height is from 0 to $2 \mathrm{~m}$, the communication range will increase significantly when the height is from 0 to $1.5 \mathrm{~m}$; however, when the height is from 1.5 to $2 \mathrm{~m}$, the communication range will not

Table 2 Communication range of wireless sensor nodes at different heights

\begin{tabular}{llllll}
\hline Placement height $(\mathrm{m})$ & 0 & 0.5 & 1 & 1.5 & 2 \\
Communication range $(\mathrm{m})$ & 23 & 32 & 52 & 57 & 58 \\
\hline
\end{tabular}


increase significantly. It suggests that its wireless communication range is proportional to placement height. However, when it reaches a certain height, the increase in communication range will become slow. This is due to the decrease in crop and other factors. However, if the placement height is too high, the experimental results are not referential, so it will be better if it can be set at $1 \mathrm{~m}$.

\subsection{Application test and results in farmland information monitoring}

After the design of two parts of the device software and hardware, next, it is necessary to collect data through experiments to verify whether the designed remote control device can complete the requirements of monitoring farmland information. In the experimental part, first, the information collected by the wireless sensor is transferred to the coordinator part through the most basic wireless network. Second, the coordinator transmits the information to the wireless communication network through the wireless information packet network module. Third, the data is transferred to the user terminal. In this part, data display and a series of operations are carried out. Since there are many wireless sensors in the farmland, only three typical sensors are selected for the test [15].

Farmland temperature and humidity collection experiment: in this experiment, because the change of temperature will change with the change of time, it is not very meaningful to only look at the continuous trend of temperature change. Through the data transmitted by the temperature and humidity sensor, the change of temperature and humidity is monitored in real time. It is only necessary to check whether the highest value of temperature and humidity in a day is still in the atmosphere suitable for farmland development. Meanwhile, it shows that the temperature value of farmland is inversely proportional to the humidity value. Figure 6 shows the highest temperature in a week and the humidity at the same time.

Farmland light intensity collection experiment: it is the same as the temperature and humidity data collection in farmland. In the light intensity collection experiment, the highest value of light intensity in a week is summarized through the data collected by the light intensity sensor. Light intensity is related to the intensity of photosynthesis

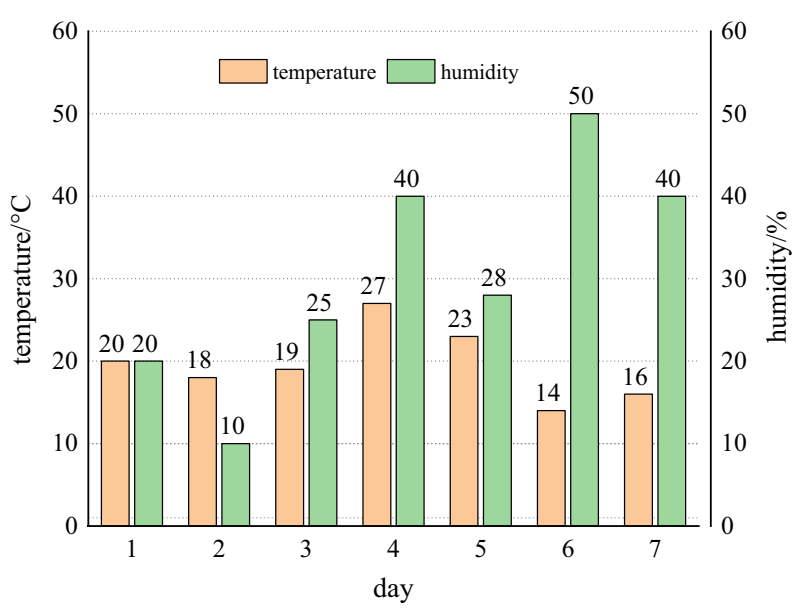

Fig. 6 Numerical images of maximum temperature and humidity of farmland at the same time in one week 
of crops in farmland, thus affecting the yield of crops in farmland. Figure 6 shows that in addition to the abnormal data values detected by individual sensor nodes at some time, the law of temperature and humidity data change obtained by sensor nodes is basically the same. In practical application, lots of sensor nodes can be deployed to obtain massive information, and mathematical methods can be used to reduce errors and improve the accuracy of monitoring data. This exploration improves the accuracy and reliability of the data by calculating the mean value of the monitoring data.

The black dot line chart in Fig. 7 shows the highest value of light intensity in a week.

Figure 7 shows that with the passage of time, the concentration of carbon dioxide in the farmland environment increases first, then decreases, and then increases. Among them, carbon dioxide concentration is the lowest on the fourth day, $200 \mathrm{ppm}$, and reaches the peak on the sixth day, $420 \mathrm{ppm}$. The results show that there is no direct correlation between light intensity and carbon dioxide concentration, and their changes are mainly affected by time. Farmland carbon dioxide concentration collection experiment: carbon dioxide concentration is an important index to investigate the farmland environment, so related data collection experiment is needed. The knowledge of biology proves that when the light intensity is the maximum, the photosynthesis of crops in the farmland also reaches the maximum, which greatly reduces the concentration of carbon dioxide in the farmland environment. Here, the concentration of carbon dioxide is determined for the time corresponding to the maximum light intensity. In Fig. 7, the white dot line graph is the corresponding numerical image.

In this design, according to the concept of the topic, the functional aspect of this device is set. First, the need to combine software and hardware to complete the required equipment is determined. In the hardware selection, various sensors, microprocessors, RF transceivers and power supplies are compared, and the devices with low power consumption and high operation ability are selected and combined. Then, in the design of software level, two aspects are considered. One is the underlying network connection and data transmission, and the other is the design for users. Finally,

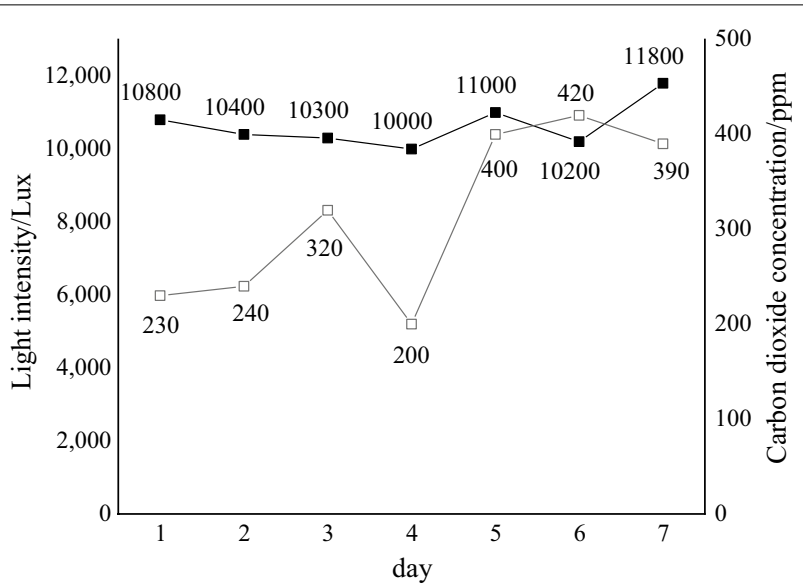

Fig. 7 The highest value of light intensity and the corresponding concentration of carbon dioxide in farmland environment in a week 
the two parts are combined to test the communication range of the device in the farmland environment. Also, the appropriate wireless sensor is selected to collect the relevant data of farmland environment, and the comparison shows that the collected data is consistent with the actual situation.

In the result and discussion, the design of remote control device based on WSN and the idea of intelligent monitoring of farmland information are completed based on the previous three aspects. First, hardware. Based on the design of four modules: sensor module, microprocessor module, RF transceiver module and power module, the hardware layout is completed to meet the requirements of the device [16]. The basic structure of the device is structured. Second, software. There are mainly two aspects: the underlying level design and the user level design. At the underlying level, the software design of coordinator, router and terminal node is completed; at the user level, the design meets the functional design of user account operation. Finally, through the combination of hardware and software, as well as the field layout of hardware and the application of software, the communication range of wireless sensor nodes is tested. Research shows that the higher the sensor is, the larger the communication range will be. In addition, three farmland related values are selected to collect and test data through corresponding wireless sensors. The final results indicate that the collected data meet the actual environment of farmland and the biological laws of farmland system.

\section{Conclusion}

Due to the rapid development of farmland agriculture and the increasing demand for functions, a remote control device based on WSN is designed to monitor farmland information. It verifies the practicability of the device. Compared with traditional monitoring methods, WSN has obvious advantages. The real-time collection of farmland temperature and humidity information through WSN can not only realize the real-time data collection and transmission, but also obtain the detailed information (such as node address) in the monitoring area, and can realize the non-human attendance. Relevant data can be obtained through remote access, information can be obtained in the office in real time, and corresponding decisions can be made. Here, there is an innovation that the designed device can achieve information monitoring of different environments by replacing different sensors. For example, the device can also be used in environmental monitoring such as mining and factory manufacturing. In the future, it can not only make some weak contribution in farmland information monitoring, but also be used in other monitoring fields to a certain extent.

A complete set of remote monitoring device has been designed, but the selected RF transceiver cannot receive a wide range. This is also related to the connection of each module in the hardware, and it is hoped that the information transmission can be completed in a longer distance in the future. On the other hand, wireless sensors may collect all the data in the process of data collection, and many of these data do not reach the critical value, which is useless for later decision-making. Therefore, it can be imagined that this part of data can be filtered out in future work. Finally, the collected data should not only be seen by users, but also be fed back to agricultural professionals. It is expected 
that these data will be handed over directly to professionals in the future, so as to make more effective suggestions for the improvement of farmland environment.

\section{Abbreviations}

WSN: Wireless sensor networks; TI: Texas instruments; STM: Synchronous transfer module; VQFN: Very-thin quad flat nolead; RF: Radio frequency.

\section{Authors' contributions}

ZJ participated in the design of the study and performed the statistical analysis. WY conceived of the study, and participated in its design and coordination and helped to draft the manuscript. All authors read and approved the final manuscript. All contributors who do not meet the criteria for authorship should be listed in an acknowledgements section. All authors read and approved the final manuscript.

\section{Funding}

Research on the Teaching Reform of Computer Graphics and Image Course of "Online Basic Knowledge + Offline Application Guidance," Project No. GS[2019]GHB2131; Funded by Gansu Province Education Science "13th Five-Year Plan" Project 2019 Annual Topic and research on Gansu Rural Tourism model and Realization Path Based on the Cultural Heritage Resources of the Silk Road Ethnic Minority Villages and Towns, project number: 2019A-012; Funded by Gansu Provincial Department of Education 2019 Institution of Higher Learning Innovation Ability Enhancement Project.

\section{Availability of data and materials}

Data sharing not applicable to this article as no datasets were generated or analyzed during the current study.

\section{Declarations}

Competing interests

The authors declare that they have no competing interests in this section.

\section{Author details}

${ }^{1}$ School of Art and Design, Lanzhou Jiaotong University, Gansu, China. ${ }^{2}$ Academy of Arts, Northwest Normal University, Gansu, China.

Received: 24 February 2021 Accepted: 26 April 2021

Published online: 10 May 2021

\section{References}

1. L. Wang, Application of wireless sensor network and RFID monitoring system in airport logistics international journal of online. Engineering 14(1), 89 (2018)

2. F. Li, H. Zhu, H. Wu, Farmland multiparameter wireless sensor network data compression strategy. Int. J. Ad Hoc Ubiq Comput. 1(1), 1 (2018)

3. W.A. Goffart, Gregory of tours: history and society in the sixth century (review). Cathol. Hist. Rev. 88(2), 325-326 (2002)

4. I.E. Onwuka, M.O. Afolabi, I.O. John et al., Design and implementation of farm monitoring and security system. Int. J. Comput. Appl. 181(9), 10-15 (2018)

5. F. Khelifi, A. Bradai, M.L. Kaddachi et al., Design and experimental implementation of monitoring system in wireless sensor networks. IET Wirel. Sens. Syst. 8(6), 350-359 (2018)

6. A. Rajput, V.B. Kumaravelu, Scalable and sustainable wireless sensor networks for agricultural application of internet of things using fuzzy-C means algorithm. Sustain. Comput. Inform. Syst. 22, 62-74 (2019)

7. Q.A. Al-Haija, I. Alfarran, A. Alabdullah et al., Design and on-field testing of wireless sensor network-based air quality monitoring system. JITCE 3(2), 54-59 (2019)

8. D. Vijayalakshmi, R. Kalaivani, Construction of minimum connected dominating set in a graph and its application in wireless sensor networks. Kongunadu Res. J. 1(2), 10-15 (2019)

9. Z. Luan, H. Fan, Design and implementation of wireless sensor cellular network based on android platform. Int. J. Online Biomed. Eng. 15(1), 18 (2019)

10. T. Wang, Z. Peng, S. Wen et al., A survey of fog computing in wireless sensor networks: concepts, frameworks, applications and issues. Ad Hoc Sens. Wirel. Netw. 44(1-2), 109-130 (2019)

11. Y.Wang, K.L. Man, K. Lee et al., Application of wireless sensor network based on hierarchical edge computing structure in rapid response system. Electronics $\mathbf{9}(7), 1176$ (2020)

12. A. Tomar, K. Nitesh, P.K. Jana, An efficient scheme for trajectory design of mobile chargers in wireless sensor networks. Wirel. Netw. 26(2), 897-912 (2020)

13. S. Kumar, S. Duttagupta, V.P. Rangan et al., Reliable network connectivity in wireless sensor networks for remote monitoring of landslides. Wirel. Netw. 26(3), 2137-2152 (2020)

14. A. Rajput, V.B. Kumaravelu, Fuzzy logic-based distributed clustering protocol to improve energy efficiency and stability of wireless smart sensor networks for farmland monitoring systems. Int. J. Commun. Syst. 33(4), e42391-e423928 (2020)

15. F. Capraro, S.R. Tosetti, P.L.C. Manrique, Sensor network for monitoring and fault detection in drip irrigation systems based on embedded systems. IEEE Lat. Am. Trans. 18(2), 383-391 (2020) 
16. H. Ye, Y. Yang, L. Zhu, A wireless network detection and control system for intelligent agricultural greenhouses based on NB-IOT technology. J. Phys. Conf. Ser. 1738(1), 012058 (2021)

\section{Publisher's Note}

Springer Nature remains neutral with regard to jurisdictional claims in published maps and institutional affiliations.

Submit your manuscript to a SpringerOpen ${ }^{\circ}$ journal and benefit from:

- Convenient online submission

- Rigorous peer review

- Open access: articles freely available online

- High visibility within the field

- Retaining the copyright to your article

Submit your next manuscript at $\boldsymbol{\nabla}$ springeropen.com 